\title{
CARBON ADDITIONS AND GRAIN DEFECT FORMATION IN HIGH REFRACTORY NICKEL-BASE SINGLE CRYSTAL SUPERALLOYS
}

\author{
S. Tin, T.M. Pollock and W.T. King* \\ University of Michigan, Dept. of Materials Science and Engineering \\ Ann Arbor, MI 48109 \\ *General Electric Power Systems
}

\begin{abstract}
Using two half fractional factorial experimental designs, the effect of alloying additions on the solidification characteristics of single crystal Ni-base superalloys has been studied in twelve distinct " 2 nd generation" type alloys. The experimental alloys, with compositional variations of $C, W$, $\mathrm{Re}, \mathrm{Ta}, \mathrm{Al}$ and $\mathrm{Hf}$, were solidified as cylindrical bars in a large cluster mold. Under constant processing conditions, nominally similar experimental alloys containing additions of 0.125 wt.\% $\mathrm{C}$ exhibited a decreased tendency to develop grain defects, such as freckle chains. The carbon additions resulted in the formation of three Ta-rich $\mathrm{MC}$ carbide morphologies which precipitate near the liquidus temperature of the alloy. Intentional carbon additions also affected the segregation behavior of the constituent elements. Comparison of distribution coefficients measured using a Scheil-type analyses revealed that less segregation of $\mathrm{W}$ and Ta occurred in the experimental single crystal alloys containing carbon. Preliminary observations suggest that carbon/carbide interactions may potentially change the segregation behavior of high density refractory alloying elements and affect the properties of the mushy zone in a manner which decreases the driving force for thermosolutal convection.
\end{abstract}

\section{Introduction}

As nickel-base single crystals are being implemented to increase efficiency in large, land-based, industrial gas turbine engines, grain defect formation during solidification has become an increasingly important problem. Typically, grain defects, such as freckles and misoriented grains, are caused by the onset of thermosolutal convective instabilities during dendritic solidification in these multicomponent alloys ${ }^{1-6}$. By achieving high thermal gradients at the growth front during solidification in the Bridgman process, these instabilities can be effectively suppressed ${ }^{1-3,5,7-11}$. However, this becomes a challenge when solidifying physically large single crystals required for land-based gas turbines. Thus, alloys with a low potential for developing these solute-induced density inversions are highly desirable.
Recent experiments with "3rd generation" typc alloys have shown that increasing tantalum and/or decreasing rhenium and tungsten levels will have a beneficial effect in reducing the number of grain defects that develop under relatively low gradient solidification conditions $^{2-4}$. Furthermore, it has also been shown that intentional carbon additions will also inhibit grain defect formation in certain high refractory alloys ${ }^{12}$. Improving the solidification characteristics of single crystal Ni-base superalloys through the addition of carbon represents a new alloying alternative with a great deal of potential. However, the effectiveness of these alloying approaches over a broader range of compositions has not yet been explored.

In this study, alloying approaches for the reduction of grain defects have been studied over a wider range of composition which covers "2nd generation" alloys such as René N5. Of particular interest was the influence of carbon on the segregation behavior of the constituent elements and the relationship between carbide precipitation and the tendency to form freckle defects. Results from detailed analyses of segregation and differential thermal analyses (DTA) of the alloys are reported. Based on these observations, a brief discussion regarding the potential interactions between carbon additions and freckling mechanisms follows.

\section{Experimental Materials and Procedure}

A total of twclve distinct alloys, listed in Table I, have been investigated in two half fractional factorial studies designed to reveal the effects of $\mathrm{Al}, \mathrm{Hf}, \mathrm{Ta}, \mathrm{Re}, \mathrm{W}$ and $\mathrm{C}$ on single crystal solidification. Each experiment was repeated to verify reproducibility. In an attempt to keep the levels of interstitial impurities constant, alloys were first sectioned from a solute-lean master heat then doped to the compositions listed in Table I. In the first matrix of experiments, referred to as Carbide Effects (CE), carbon, tantalum and hafnium levels for alloys varied form 0 to $0.125 \mathrm{wt} \%, 4.0$ to $8.0 \mathrm{wt} \%$ and 0 to $0.3 \mathrm{wt} \%$, respectively. In the second matrix, or Main Effects (ME) experiments, levels of carbon, aluminum, tungsten and rhenium in the alloys 
Table I: Compositions of Experimental Single Crystal Alloys (wt.\%)

\begin{tabular}{c|c|c|c|c|c|c|c|c|c|c}
\hline & C & Al & Ta & Hf & W & Re & Mo & Cr & Co & Ni \\
\hline \hline ME-1 & 0.000 & 6.8 & 6.1 & 0.14 & 2.4 & 4.6 & 1.5 & 7.0 & 7.5 & Bal. \\
ME-2 & 0.000 & 6.7 & 6.1 & 0.14 & 2.3 & 4.6 & 1.5 & 7.0 & 7.5 & Bal. \\
ME-3 & 0.000 & 6.7 & 6.0 & 0.13 & 7.3 & 1.4 & 1.5 & 7.0 & 7.5 & Bal. \\
ME-4 & 0.000 & 6.7 & 6.1 & 0.14 & 7.2 & 1.4 & 1.5 & 7.0 & 7.5 & Bal. \\
ME-5 & 0.000 & 4.4 & 6.0 & 0.12 & 7.2 & 4.4 & 1.5 & 7.0 & 7.5 & Bal. \\
ME-6 & 0.000 & 4.4 & 6.0 & 0.13 & 7.1 & 4.5 & 1.5 & 7.0 & 7.5 & Bal. \\
ME-7 & 0.000 & 4.8 & 6.4 & 0.14 & 2.5 & 1.5 & 1.5 & 7.0 & 7.5 & Bal. \\
ME-8 & 0.000 & 4.9 & 6.5 & 0.14 & 2.5 & 1.5 & 1.5 & 7.0 & 7.5 & Bal. \\
ME-9 & 0.125 & 6.5 & 5.8 & 0.14 & 7.0 & 4.5 & 1.5 & 7.0 & 7.5 & Bal. \\
ME-10 & 0.119 & 6.4 & 5.8 & 0.14 & 7.0 & 4.4 & 1.5 & 7.0 & 7.5 & Bal. \\
ME-11 & 0.127 & 4.6 & 6.2 & 0.14 & 7.4 & 1.4 & 1.5 & 7.0 & 7.5 & Bal. \\
ME-12 & 0.129 & 4.5 & 6.1 & 0.14 & 7.4 & 1.4 & 1.5 & 7.0 & 7.5 & Bal. \\
ME-13 & 0.132 & 4.6 & 6.2 & 0.14 & 2.4 & 4.7 & 1.5 & 7.0 & 7.5 & Bal. \\
ME-14 & 0.135 & 4.7 & 6.2 & 0.15 & 2.4 & 4.8 & 1.5 & 7.0 & 7.5 & Bal. \\
ME-15 & 0.140 & 7.1 & 6.2 & 0.15 & 2.4 & 1.5 & 1.5 & 7.0 & 7.5 & Bal. \\
ME-16 & 0.130 & 7.0 & 6.2 & 0.14 & 2.4 & 1.4 & 1.5 & 7.0 & 7.5 & Bal. \\
CE-1 & 0.000 & 5.6 & 8.4 & 0.00 & 4.5 & 2.8 & 1.5 & 7.0 & 7.5 & Bal. \\
CE-2 & 0.000 & 5.5 & 8.1 & 0.00 & 4.3 & 2.8 & 1.5 & 7.0 & 7.5 & Bal. \\
CE-3 & 0.000 & 5.8 & 4.0 & 0.28 & 4.6 & 2.9 & 1.5 & 7.0 & 7.5 & Bal. \\
CE-4 & 0.000 & 5.8 & 3.9 & 0.31 & 4.7 & 3.1 & 1.5 & 7.0 & 7.5 & Bal. \\
CE-5 & 0.139 & 5.8 & 3.9 & 0.00 & 4.8 & 3.0 & 1.5 & 7.0 & 7.5 & Bal. \\
CE-6 & 0.140 & 5.8 & 4.0 & 0.00 & 4.8 & 3.0 & 1.5 & 7.0 & 7.5 & Bal. \\
CE-7 & 0.130 & 5.5 & 8.2 & 0.27 & 4.5 & 2.8 & 1.5 & 7.0 & 7.5 & Bal. \\
CE-8 & 0.119 & 5.4 & 8.4 & 0.26 & 4.5 & 2.9 & 1.5 & 7.0 & 7.5 & Bal. \\
\hline
\end{tabular}

ranged from 0 to $0.1 \mathrm{wt} . \%, 4.5$ to $7.0 \mathrm{wt} . \%, 2.5$ to $7.0 \mathrm{wt} \%$ and 1.5 to 5.0 wt. $\%$, respectively.

For each experimental alloy, fourteen cylindrical bars approximately $15 \mathrm{~cm}$ in length with diameters of 12.7 , 15.9 and $19.0 \mathrm{~mm}$ were unidirectionally solidified in a large investment cluster mold by PCC Airfoils. Processing parameters used in these experiments were designed such that solidification occurred under relatively low thermal gradient conditions. The variations in bar diameters resulted in characteristic thermal gradients which allowed for the simulation of three different solidification conditions under a constant withdrawal rate of $20 \mathrm{~cm} / \mathrm{hr}$.

Following solidification, as-cast specimens were macroetched in a hot nitric bath to reveal the presence of freckles and misoriented grains. Selected bars were then sectioned normal to the solidification direction to determine the characteristic primary dendrite arm spacings associated with the varying bar diameters.

For each of the carbon containing alloys, small rectangular samples $(\sim 5 \mathrm{~g})$ were sectioned from the bars and prepared for electrolytic extraction of the carbides. Using a small sheet of platinum as the cathode and a current density of $0.04 \mathrm{~A} / \mathrm{cm}^{2}$, the $\gamma-\gamma$ ' matrix was dissolved in a solution of 9:1 Methanol: $\mathrm{HCl}$ with $1 \mathrm{wt} \%$ tartaric acid. The remaining carbides were then collected and analyzed in a Rigaku X-ray Diffractometer (XRD). A Phillips XL30 FEG scanning electron microscope (SEM) was used to characterize the carbide morphologies and perform qualitative energy dispersive spectroscopy (EDS) on the carbides.

A two step process was used to characterize segregation of individual alloying elements and to subsequently assess distribution coefficients, $\mathrm{k}$, via a Scheil analysis. This technique is similar to the ranking technique reported by Gungor, Huang and Nastac ${ }^{13-15}$. As-cast samples were first sectioned normal to the $<001>$ growth direction. Next, a line scan that crossed the dendrite core into the interdendritic region was used to determine whether individual elements segregate preferentially to the dendrite core or the interdendritic region. A second series of analyses were then conducted to measure composition at points in a square grid composed of 225 points. The grid was placed over a representative section of the dendritic microstructure, covering $\sim 1.2 \mathrm{~mm}^{2}$. The composition data acquired for the individual elements were then ranked in order according to their characteristic segregation behavior. For elements determined to have distribution coefficients greater than one, as determined previously by the linescan, the composition data was ranked in descending order and plotted as apparent fraction solid, yielding a Scheil plot. Composition data for elements segregating to the interdendritic regions were ranked in ascending order and plotted in the same manner. Distribution coefficients were then extracted by fitting the plots with a Scheil equation [1] and/or a modified Scheil analysis [2] which accounts for back diffusion, 


$$
\begin{aligned}
& C_{s}=k C_{o}\left(1-f_{s}\right)^{k-I} \\
& C_{s}=k C_{o}\left(1-(1-2 a k) f_{s}\right)^{k-1 / 1-2 a k}
\end{aligned}
$$

where $C_{s}$ is the local composition of the solid, $C_{o}$ is the nominal alloy composition, $\alpha$ is the Fourier number, and $f_{s}$ is the fraction solid. This analysis assumes that the data collected was representative of the entire sample and that the distribution coefficients were constant. Steps were taken to determine the validity of these assumptions. First, the mean composition from the EDS point measurements were compared to the actual compositions of the different samples measured using X-ray Fluorescence (XRF). Experimental Scheil plots generated from the point measurements were also compared to theoretical Scheil plots with constant $\mathbf{k}$ values to detect any deviations between the two curves. All quantitative EDS measurements in these analyses were carried out on a Philips XL30 FEG SEM.

Finally, a SETARAM SETSYS 18 Differential Thermal Analysis unit was used to investigate the effects of alloying composition on alloy solidus, liquidus and carbide precipitation temperatures. Prior to testing of the experimental alloys, the DTA unit was calibrated with high purity $\mathrm{Ni}(99.99+\%)$ and $\mathrm{Ag}(99.9999 \%)$ at scanning rates of $3,5,10$ and $20^{\circ} \mathrm{C} / \mathrm{min}$ using a platinum reference. All tests were conducted in a purged ultra-high purity argon atmosphere (flow rate $\sim 70 \mathrm{cc} / \mathrm{min}$ ) using high purity alumina crucibles. Once calibrated, cylindrical samples $(4 \mathrm{~mm}$ diameter and $\sim 3-4 \mathrm{~mm}$ height) with masses ranging from 200 $250 \mathrm{mg}$ were prepared from the various alloys. Due to the effects of undercooling, only the DTA traces collected during heating were evaluated. The heating cycle of the samples consisted of:

1) RT to $1000^{\circ} \mathrm{C}$ at $20^{\circ} \mathrm{C} / \mathrm{min}$

2) $10 \mathrm{~min}$ isothermal soak at $1000^{\circ} \mathrm{C}$

3) $1000^{\circ} \mathrm{C}$ to $1550^{\circ} \mathrm{C}$ at $5^{\circ} \mathrm{C} / \mathrm{min}$

For this particular application, a scanning rate of $5^{\circ} \mathrm{C} / \mathrm{min}$ was determined to yield the best combination of temperature accuracy and peak resolution. Additionally, this heating/cooling rate matched the calculated solidification rate of the $12.7 \mathrm{~mm}$ diameter bars. Following the DTA experiments, the samples were metallographically prepared and examined to ensure that no major contamination or interaction with the alumina crucibles occurred during the analyses.

\section{Results}

Figure 1 shows as-solidified bars of alloy ME1 with diameters of $12.7,15.9$ and $19.0 \mathrm{~mm}$. The bars exhibit both freckles and larger, misoriented grains. Both types of defects have previously been shown to form due to the onset of thermosolutal convective instabilities during

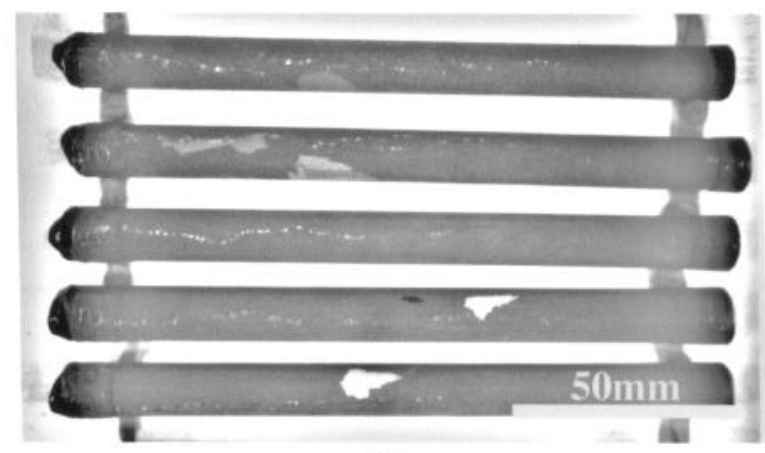

(a)

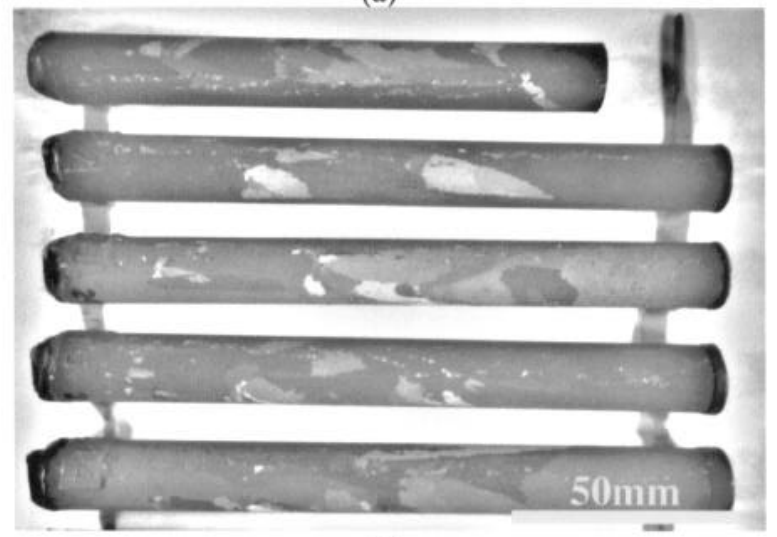

(b)

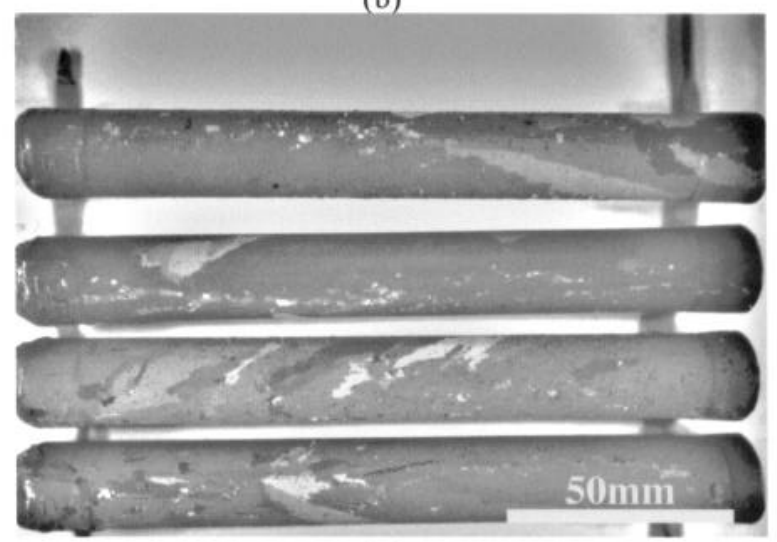

(c)

Figure 1: Photos of the macroetched castings exhibiting freckling and the development of misoriented grains in (a) $12.7 \mathrm{~mm}$, (b) $15.9 \mathrm{~mm}$ and (c) $19.0 \mathrm{~mm}$ diameter bars.

solidification ${ }^{4}$. From this, it is apparent that the number of grain defects increased as the cross-sectional area of the casting increased. In addition, micrographs of the as-cast solidified microstructure, Figure 2 , revealed that the primary dendrite arm spacing measurements (PDAS) increased with the diameter of the bars. On average for all alloys, the PDAS of the $12.7,15.9$ and $19.0 \mathrm{~mm}$ diameter bars were measured to be 340,400 and $460 \mu \mathrm{m}$, respectively. Figure 3 shows the average number of freckle-type grain defects as a function of alloy composition for the fractional factorial studies. The beneficial effects of both tantalum and carbon are evident 


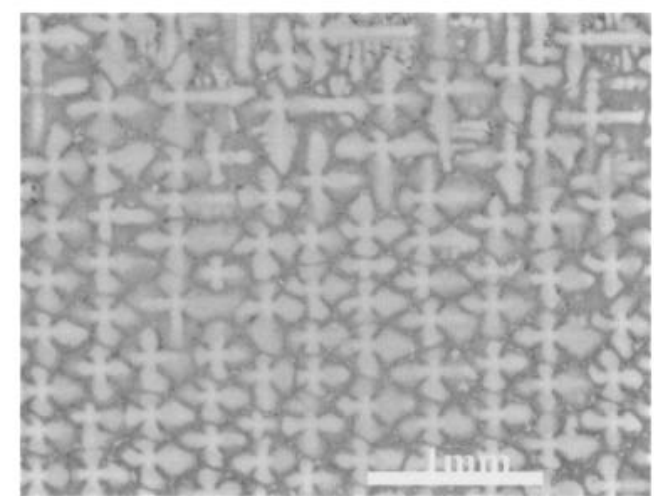

(a)

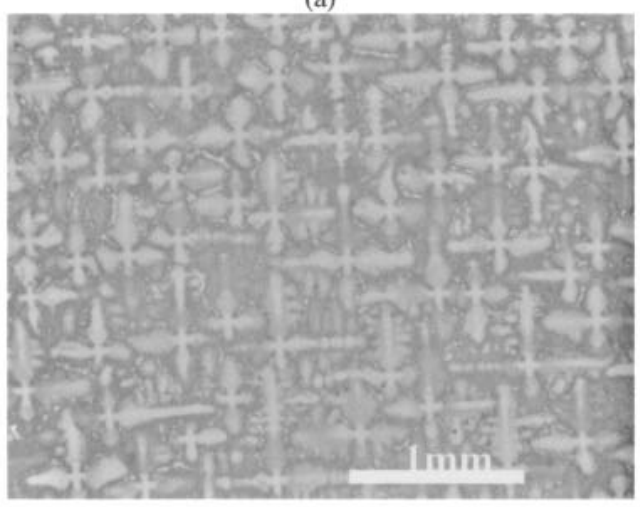

(b)

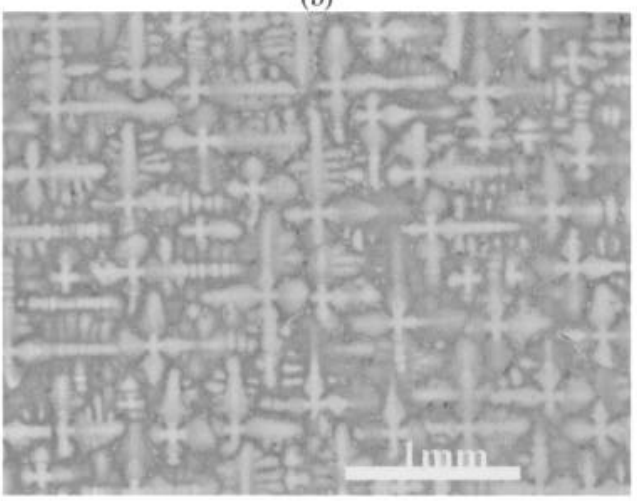

(c)

Figure 1: Typical dendritic microstructure of as-cast samples sectioned normal to the solidification direction with diameters of (a) $12.7 \mathrm{~mm}$, (b) $15.9 \mathrm{~mm}$ and (c) $19.0 \mathrm{~mm}$.

from the solidification experiments involving alloys from the CE matrix, Figure 3a. All of these alloys were René N5based with nominally identical levels of $\mathrm{Cr}, \mathrm{Co}, \mathrm{Al}, \mathrm{W}, \mathrm{Re}$ and Mo. For example, comparison of alloys CE1 and 2 to CE3 and 4 clearly shows that freckling was reduced when the level of $\mathrm{Ta}$ in the alloy increases from 4.0 to $8.3 \mathrm{wt} \%$. Interestingly, the beneficial effect from the addition of 0.125 wt. \% $\mathrm{C}$ to the alloys varied dramatically between alloys CE5 and 6 compared to CE7 and 8 . In alloys CE5 and 6, which contain $\sim 3.9 \mathrm{wt} . \%$ Ta, the number of freckle defects observed on the surface of the castings decreased only slightly with

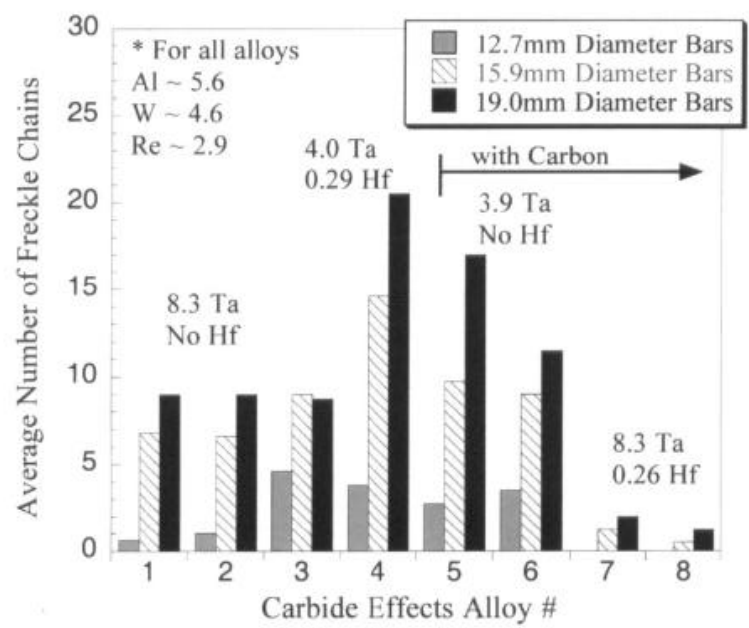

(a)

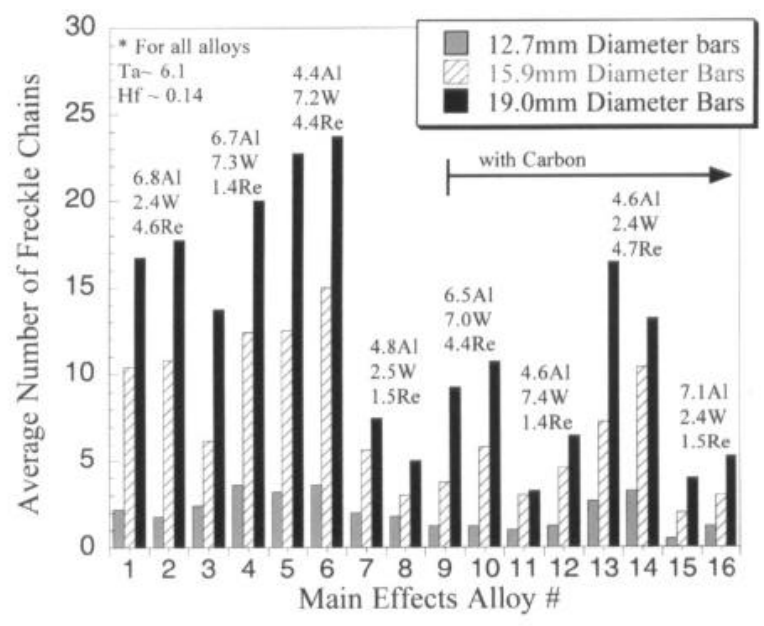

(b)

Figure 2: Results from the half fractional factorial solidification experiments involving (a) the CE and (b) the ME matrix of alloys.

the addition of carbon. However, the carbon addition was very effective in minimizing freckle defects in the alloys with 8.3 wt.\% Ta. Comparison of alloys CE1 and 2 to CE7 and 8 shows that freckling was essentially eliminated in the $12.7 \mathrm{~mm}$ diameter bars and was greatly reduced in the 15.9 and $19.0 \mathrm{~mm}$ bars by the addition of carbon.

Results from the ME matrix of experiments are shown in Figure 3b. General trends indicate that increasing levels of $\mathrm{W}$ and $\mathrm{Re}$ promote the development of freckle defects while intentional $\mathrm{C}$ additions of $0.125 \mathrm{wt} . \%$ suppress them. Alloys used for these experiments were also René N5based with nominally identical levels of $\mathrm{Cr}, \mathrm{Co}, \mathrm{Mo}, \mathrm{Hf}$ and 


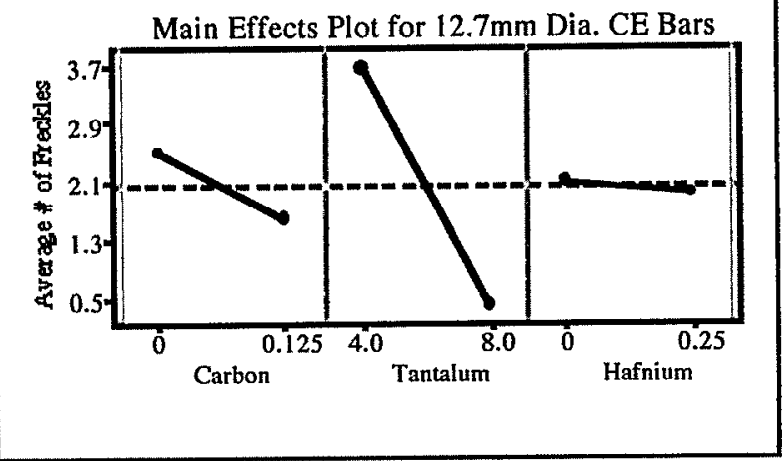

(a)

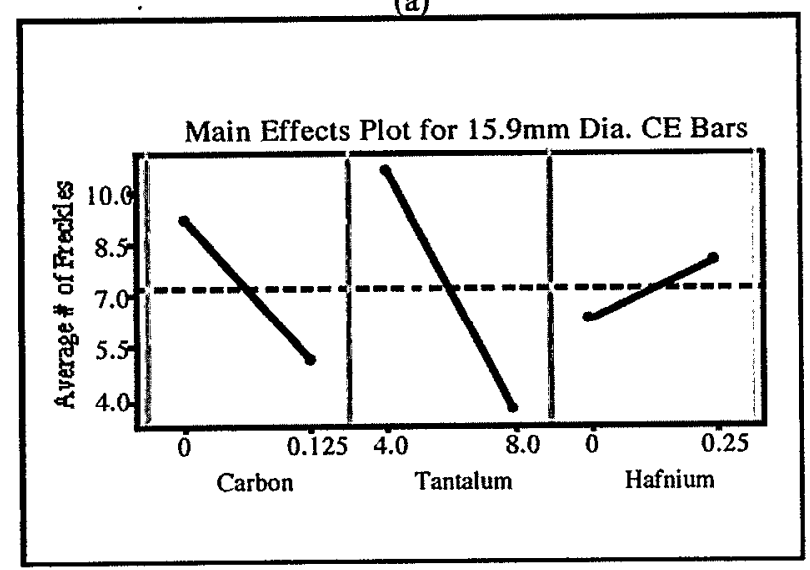

(b)

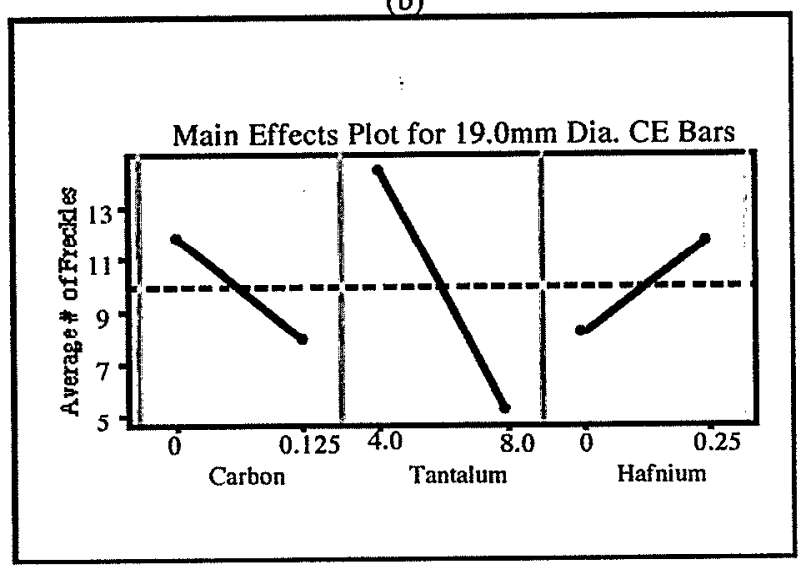

(c)

Ta. Comparison of alloys ME1 through 8 reveals that the onset of convective instabilities was most prevalent in alloys with elevated levels of $\mathrm{W}$ and $\mathrm{Re}$. In comparative instances, alloys with the intentional carbon additions, ME9 through 16, exhibited fewer freckle defects on the surface of the casting. However, the effectiveness of the carbon addition in suppressing grain defect formation again varied from alloy to alloy. In this instance, the beneficial effect of the carbon addition is shown to be much more significant in the alloys which contain elevated levels of W, ME9 through 12. The degree of freckling on the surfaces of the castings

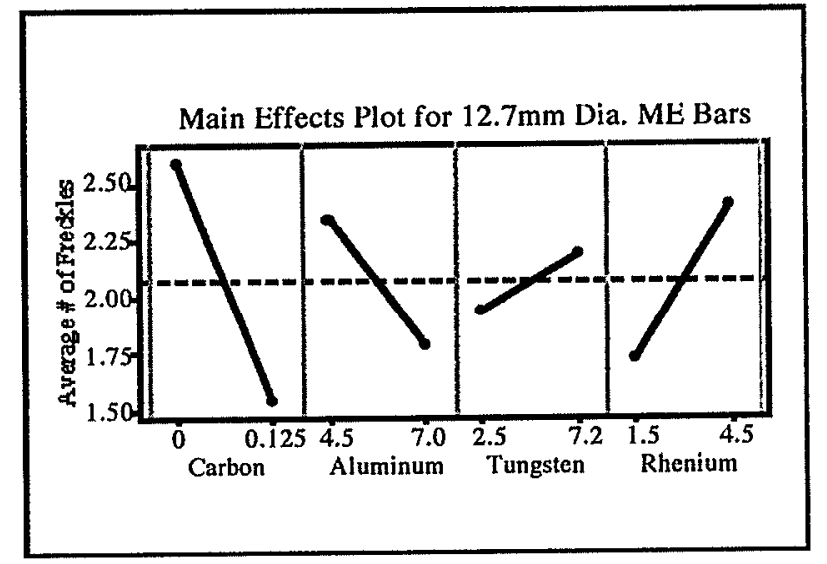

(d)

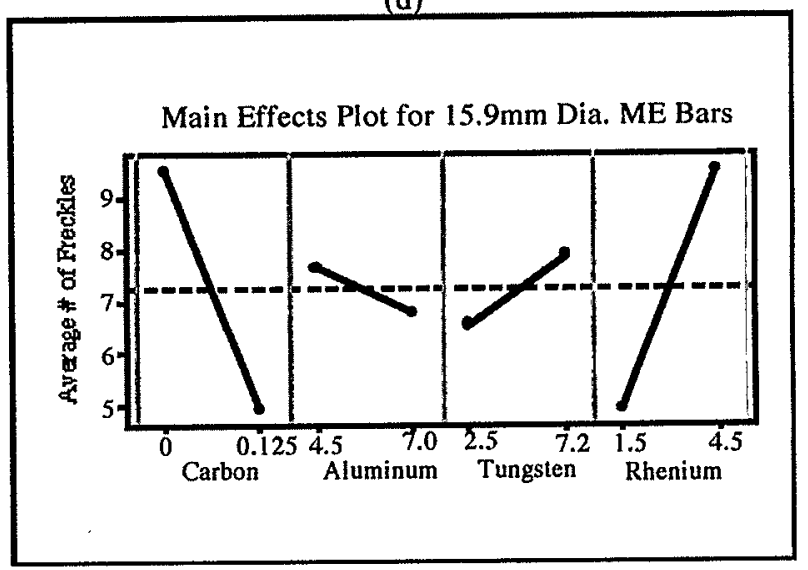

(e)

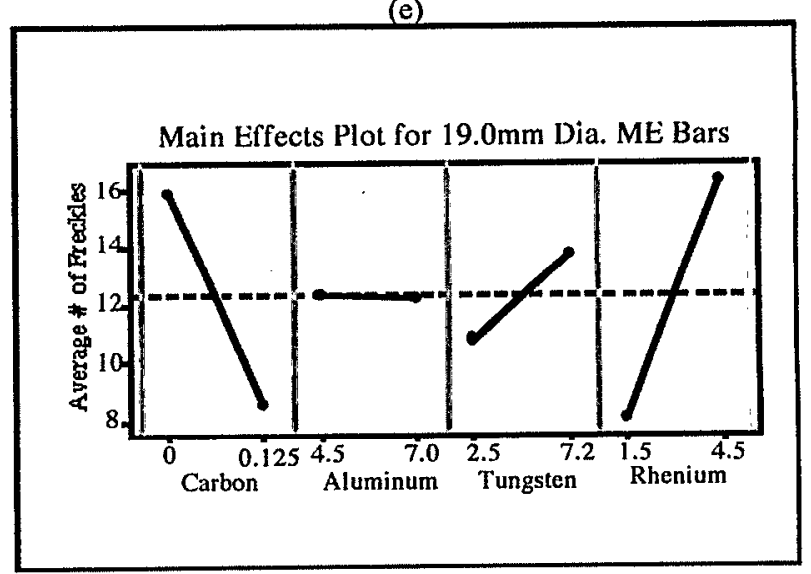

(f)

Figure 4: Main Effects plots generated using the results from (a) CE $12.7 \mathrm{~mm}$, (b) CE $15.9 \mathrm{~mm}$, (c) CE $19.0 \mathrm{~mm}$, (d) $\mathrm{ME}$ $12.7 \mathrm{~mm}$, (e) ME $15.9 \mathrm{~mm}$ and (f) ME $19.0 \mathrm{~mm}$ diameter bars.

with $\sim 2.4$ wt.\% W, ME13 through 16, was observed to be only slightly lower than comparable alloys containing no carbon additions.

To statistically assess the influence of individual elements within the two sets of designed experiments, a commercially available statistical software package, MINTAB, was used to generate Main Effects plots, Figure 4. 
In factorial experiments, such as these where the variables are systematically changed, these plots isolate the response of each variable. For the $\mathrm{CE}$ alloys, Figures $4 \mathrm{a}-\mathrm{c}$ clearly indicate that increasing Ta levels in the alloys from 4.0 to $8.0 \mathrm{wt} . \%$ played a major role in inhibiting the onset of freckle formation. Due to a large two factor interaction between $\mathrm{C}$ and $\mathrm{Hf}$ in the $\mathrm{CE}$ matrix, their effects cannot be evaluated separately. However, results from the ME matrix, Figures $4 \mathrm{~d}-$ $\mathrm{f}$, reveal that the effect of $\mathrm{C}$ was indeed beneficial with respect to stabilizing against the onset of convective instabilities. In addition, freckle defects are shown to increase with elevated Re and W levels. Finally, changes in Al content become statistically insignificant as thermal gradients decrease in the larger diameter bars.

In all instances, carbon additions to the experimental alloys resulted it the formation of a small volume fraction of carbides located preferentially in the interdendritic regions, surrounded by a $\gamma-\gamma^{\prime}$ matrix. Extraction of carbides present in "2nd generation" alloys revealed morphologies that are identical to those observed in "3rd generation" René N6-based alloys. As seen in Figure 5, the three morphologies were characterized as blocky, script and nodular. Most of the experimental alloys contained a mixture of both script and nodular carbides. No correlation between carbide morphology and freckling was evident. XRD and EDS analyses identified these carbides to be Ta-rich MC carbides, with lattice parameters varying from 4.39 to 4.45 angstroms depending on the presence of minor amounts of $\mathrm{Hf}, \mathrm{Ni}, \mathrm{Cr}, \mathrm{Co}$, and Mo.

Due to a potential change in the solidification path of the alloy as a result of the precipitation of Ta-rich MC carbides, the segregation characteristics of the constituent elements were studied in the as-cast crystals. Quantitative EDS linescans through the dendrite core and interdendritic regions revealed that $\mathrm{Ta}$ and $\mathrm{Al}$ segregate preferentially to the interdendritic region, while $\mathrm{W}, \mathrm{Re}, \mathrm{Co}, \mathrm{Cr}$ and Mo segregate to the dendrite core.

Comparison of the Scheil analyses of tantalum for a pair of nominally similar alloys with and without carbon is shown in Figure 6. Initially, the two curves are nearly identical, suggesting that solidification is progressing in the same manner for the two alloys. However, separation of the curves occurs at approximately 0.5 apparent fraction solid, corresponding to the onset of Ta-rich MC carbide precipitation in the mushy zone. The $1.5-2 \mathrm{wt} . \%$ ( $\sim 0.6$ at.\%) deviation in the curves is consistent with the $\mathrm{TaC}$ reaction, consuming the $0.125 \mathrm{wt} \%(0.6$ at.\%) carbon in solution. The difference in the overall slope of the two curves is captured by the fitted distribution coefficient, $\mathrm{k}$. Using the modified Scheil equation to account for limited back diffusion ( $\alpha=$ 0.01 ), the fitted distribution coefficients for CE1 and CE8 are 0.71 and 0.80 , respectively. Although comparison of the

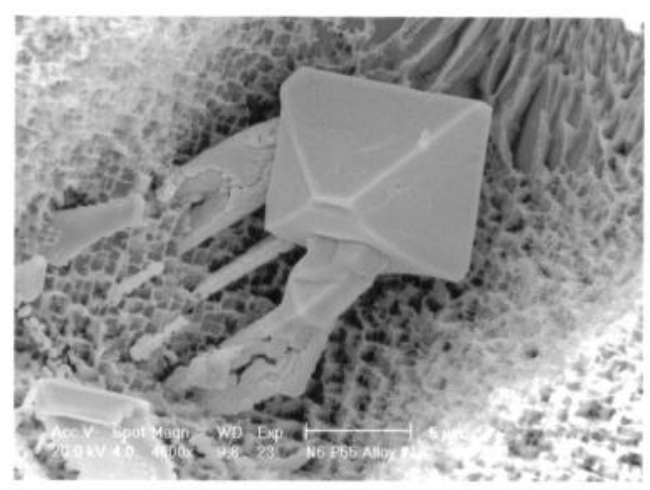

(a)

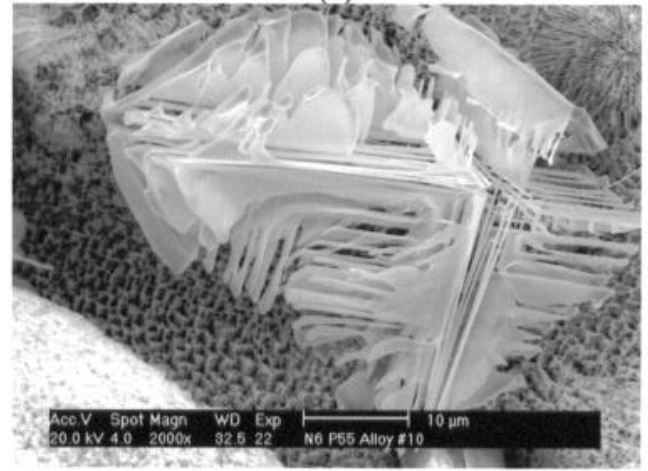

(b)

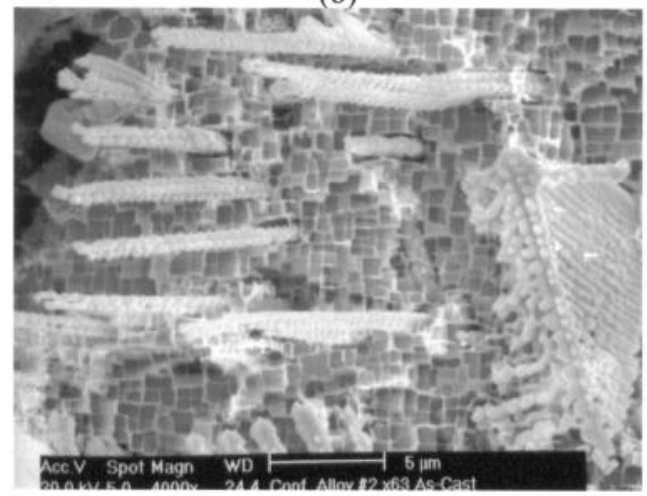

(c)

Figure 5: Photomicrographs of Ta-rich MC carbide morphologies seen in both René N5 and N6 - based alloys: (a) blocky, (b) script and (c) nodular.

segregation coefficients in Table II show that less segregation of the constituent elements occurred in alloys which contain carbon, the degree to which the elements were affected varied. Generally, the largest changes in segregation due to carbon were observed in Ta and W. Since carbides contain a significant amount of $\mathrm{Ta}$, the change in $\mathrm{Ta}$ segregation was not unexpected. However, W segregation is altered by the presence of carbon in spite of the fact that no W could be detected in the carbides. As mentioned earlier, the ME alloys in which the carbon additions were determined to be most effective in suppressing the onset of convective instabilities also had elevated levels of W. 
DTA analyses of the as-cast experimental single crystal alloys revealed information on the effects of alloy composition on solidus, liquidus and carbide dissolution temperatures. Comparison of alloys CE4 and CE5 in Figure $7 \mathrm{a}$, which are essentially nominally similar alloys except for the addition of $0.125 \mathrm{wt} \% \mathrm{C}$ to $\mathrm{CE} 5$, reveal that carbon lowers the liquidus temperature of the alloy by $\sim 7^{\circ} \mathrm{C}$. Furthermore, it results in the dissolution of the Ta-rich $\mathrm{MC}$ carbides at approximately $24^{\circ} \mathrm{C}$ below the liquidus temperature of the alloy. As seen in Figure $7 \mathrm{~b}$, increasing the level of Ta dramatically lowers the liquidus temperature of the alloys by approximately $15^{\circ} \mathrm{C}$. Although the liquidus temperatures of the alloys are significantly different, carbide dissolution in alloys CE5 through 8 occur at the same temperature, $1385^{\circ} \mathrm{C}$. Collective results of the DTA analyses, Table III, show that the carbide dissolution temperatures $\left(1377-1393^{\circ} \mathrm{C}\right)$ are much less sensitive to shifts in composition than the solidus $\left(1331-1391^{\circ} \mathrm{C}\right)$ and liquidus $\left(1381-1428^{\circ} \mathrm{C}\right)$ temperatures.

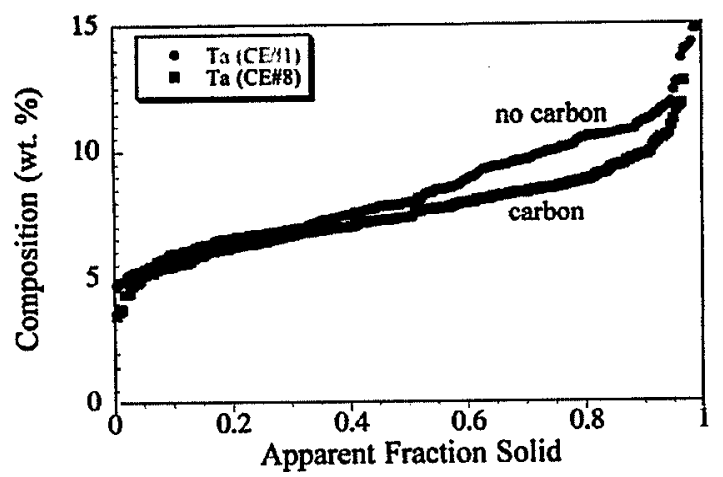

Figure 6: Comparison of tantalum distribution in alloys $\mathrm{CE} 1$ and CE8.

\section{Discussion}

The results of experiments reported here on " $2 \mathrm{nd}$ generation" type alloys as well as results of previous experiments on "3rd generation" type alloys clearly show that intentional carbon additions to high refractory single crystal alloys assist in minimizing grain defect formation. However, the effects of carbon on the mechanisms which result in freckling are not yet well understood. One potential mechanism by which carbon improves solidification characteristics is by a change in segregation behavior of other constituent elements. Changes in segregation lead to slight compositional changes in the interdendritic liquid which may possibly lower the tendency for the onset of convective instabilities. Keeping in mind the variable factors in the ME alloys, comparison of the results from the solidification experiments show that alloys ME9\&10 and ME11\&12 have significantly improved solidification characteristics when compared to ME5\&6 and ME3\&4,

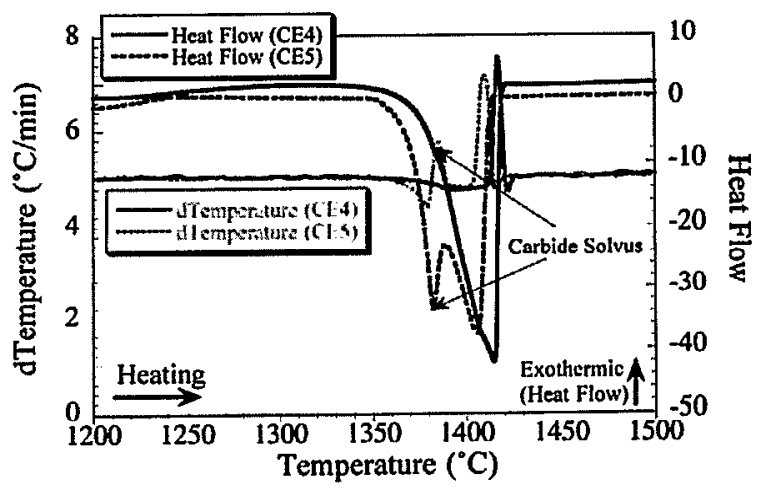

(a)

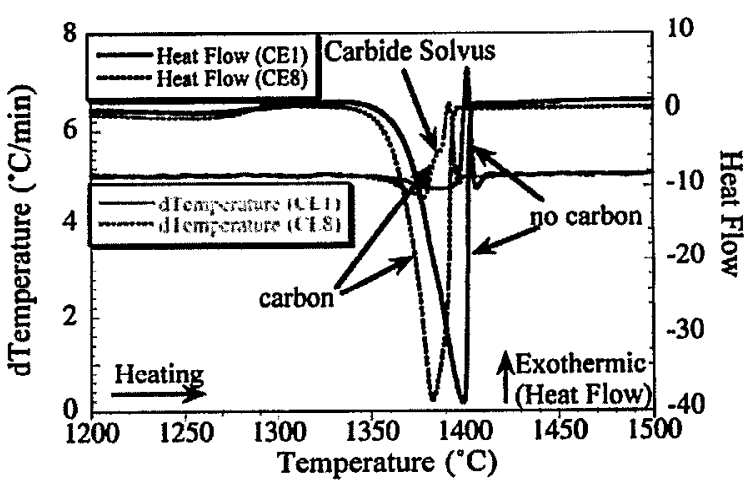

(b)

Figure 7: DTA traces from single crystal alloys (a) CE4 and CE5 (b) CE1 and CE8.

respectively. Since the effect of $\mathrm{Al}$ has been previously shown to be negligible, especially as thermal gradients decrease, these improvements can be attributed to the carbon addition. Relative to the effects of $W$, Re and Ta additions, previous studies involving "3rd generation" René N6-based alloys have also shown that minor variations in Al levels were statistically insignificant with respect to freckle formation $^{2,12}$. Comparison of ME13\&14 and ME15\&16 with ME1\&2 and ME7\&8 show that the beneficial effects of the carbon addition are much less significant in alloys with low levels of W. Recalling the segregation analyses, the constituent elements most affected by the carbon additions were $\mathrm{Ta}$ and $\mathrm{W}$. The alloys which benefit to the greatest degree from the $\mathrm{C}$ addition have the strongest segregation of Ta combined with the weakest segregation of W. Typically, elevated levels of $\mathrm{W}$ would promote freckling due to its tendency to segregate to the dendrite core and create a density inversion between the interdendritic liquid and the bulk melt ${ }^{2,4}$. However, in this case, the addition of carbon results in less segregation of $W$ to the dendrite core thereby lowering the alloys' tendency to develop convective instabilities. In alloys ME1\&2, ME7\&8 and ME13 through 16 the presence of only $\sim 2.4 \mathrm{wt} . \% \mathrm{~W}$ in the alloys would not seem likely to contribute significantly to the formation of 
Table II: Fitted Distribution Coefficients for Experimental Alloys

\begin{tabular}{l|c|c|c|c|c|c|c|c|c|c|c|c}
\hline & $C E \# 4$ & $C E \# 5$ & $C E \# I$ & $C E \# 8$ & ME\#6 & ME\#10 & ME\#4 & ME\#II & ME\#2 & ME\#I4 & ME\#7 & ME\#I5 \\
\hline \hline $\boldsymbol{A l}$ & 0.89 & 0.88 & 0.85 & 0.86 & 0.89 & 0.89 & 0.92 & 0.92 & 0.92 & 0.95 & 0.94 & 0.95 \\
$\boldsymbol{C} \boldsymbol{r}$ & 1.12 & 1.13 & 1.15 & 1.15 & 1.07 & 1.15 & 1.15 & 1.06 & 1.13 & 1.06 & 1.07 & 1.13 \\
$\boldsymbol{C o}$ & 1.10 & 1.08 & 1.10 & 1.10 & 1.05 & 1.09 & 1.09 & 1.04 & 1.07 & 1.04 & 1.05 & 1.09 \\
$\boldsymbol{N i}$ & 0.97 & 0.98 & 0.97 & 0.97 & 0.96 & 0.94 & 0.96 & 0.98 & 0.97 & 0.97 & 0.98 & 0.98 \\
$\boldsymbol{T} \boldsymbol{a}$ & 0.67 & 0.76 & 0.72 & 0.77 & 0.79 & 0.87 & 0.76 & 0.89 & 0.78 & 0.89 & 0.78 & 0.84 \\
$\boldsymbol{W}$ & 1.39 & 1.25 & 1.39 & 1.35 & 1.38 & 1.31 & 1.36 & 1.28 & 1.54 & 1.35 & 1.58 & 1.40 \\
$\boldsymbol{R} \boldsymbol{e}$ & 1.39 & 1.39 & 1.42 & 1.34 & 1.35 & 1.30 & 1.38 & 1.28 & 1.37 & 1.30 & 1.25 & 1.23 \\
$\boldsymbol{M o}$ & 1.25 & 1.28 & 1.30 & 1.30 & 1.20 & 1.27 & 1.25 & 1.20 & 1.23 & 1.18 & 1.13 & 1.24 \\
\hline
\end{tabular}

convective instabilities. Thus, a decreased degree of W segregation in these alloys apparently does not provide substantial benefits in improving the solidification characteristics. On the other hand, in alloys ME3 through 7 and ME9 through 12 (>7.0 wt.\% W) where W would likely be considered to contribute heavily to freckle formation, changes in segregation could potentially improve solidification characteristics substantially. Similar changes in segregation behavior of $\mathrm{W}$ due to carbon have also been recently reported in experimental " 3 rd generation" single crystal superalloys ${ }^{12}$.

Interestingly, the consumption of tantalum by the $\mathrm{TaC}$ carbide reaction during solidification is beneficial with respect to the solidification characteristics of the alloy. During solidification, tantalum segregates preferentially to the interdendritic regions and offsets the density imbalance which develops between the solute in the mushy zone and the bulk liquid. Previous studies have shown that decreasing the levels of tantalum in the mushy zone leads to an increased propensity for the onset of thermosolutal convection ${ }^{2,4}$. However, since the density of $\mathrm{TaC}$ (14.5 $\left.\mathrm{gm} / \mathrm{cm}^{3}\right)$ is almost twice that of the bulk liquid, the presence of these high density carbides in the mushy zone during solidification may also be beneficial in stabilizing convective fluid flow.

In the CE matrix of experiments, levels of $\mathrm{Ta}, \mathrm{C}$ and $\mathrm{Hf}$ were varied in the alloys while all of the other constituents were held constant. The most obvious result from Figures $3 a$ and $4 a-c$ is that increasing the level of $\mathrm{Ta}$ in the alloy suppresses the onset of thermosolutal convection. In the results, the effect of $\mathrm{Hf}$ on the solidification characteristics was negligible. Although, $\mathrm{Hf}$ is a very potent MC carbide former, it was concluded that the presence of only $\sim 0.3$ wt. $\% \mathrm{Hf}(\sim 0.1$ at. $\%)$ was insufficient to generate drastic changes, since it would consume only $\sim 0.02 \mathrm{wt} \% \mathrm{C}$ $(0.1$ at. \%) in the alloy. With $\sim 4.5$ wt.\% W present in the CE alloys, the change in the segregation behavior of $\mathrm{W}$ due to carbon had little effect in reducing the number of freckles in alloys CE5 and 6. However, a substantial decrease in the number of freckles was observed between alloys CE1\&2 and CE7\&8. Clearly, in this instance, the carbon addition to alloys CE7 and 8 is affecting a mechanism of freckle formation other than the segregation behavior of the constituent elements. Even though larger differences in W segregation were measured between alloys CE4 and CE5, no significant beneficial effect due to carbon was observed between alloys CE3\&4 and CE5\&6. Factoring in the DTA data, differences between the relative carbide dissolution temperatures of CE5\&6 and CE7\&8 are readily observed. Considering the sequence of events which begin with the initiation of the convective instabilities and ultimately result in freckle formation, it seems highly probable that carbide formation close to the liquidus temperature could potentially affect freckling mechanisms. Carbide dissolution in alloys CE7\&8 and CE5\&6 occur at $\sim 8^{\circ} \mathrm{C}$ and $\sim 24^{\circ} \mathrm{C}$ below their respective alloy liquidus temperatures. Referring back to the carbon containing alloys in the ME experiments, even though alloys ME9 and 10 had the highest potential for developing freckles based on composition, more freckle defects were observed on the castings from alloys ME13 and 14. In this case, the relative carbide dissolution temperatures in ME9\&10 and ME13\&14 were $\sim 8^{\circ} \mathrm{C}$ and $22^{\circ} \mathrm{C}$, respectively.

Along with the possibility of influencing the segregation behavior of the constituent elements, the resulting carbide precipitation may serve to alter the viscosity and permeability of the interdendritic fluid. Investigations of freckling in transparent and binary alloy systems have shown that the onset of thermosolutal convection occurs in the upper regions of the mushy zone where the fraction solid in no greater than $\sim 0.5^{5,6,16-18}$. At higher fraction solid, the permeability of the dendritic network is too low for solute induced fluid flow to develop. Thus, changes to the upper regions of the mushy zone, such as the precipitation of carbides just below the liquidus, should theoretically lower the permeability and decrease the alloys' tendency to develop freckles.

To summarize, this study suggests that some of the inherent difficulties in casting single crystal blades can be lessened through slight modifications in alloy composition. Although freckles and other grain defects can potentially be reduced by optimizing the levels of $\mathrm{Ta}, \mathrm{Re}$, and $\mathrm{W}$, this is unlikely to simultaneously benefit phase stability, corrosion, creep, and fatigue properties. Therefore, alloying approaches, which involve changes in "minor" alloying 
elements such as carbon, may be more useful for reducing grain defects without significantly compromising mechanical or physical properties. These results reveal that carbon additions are beneficial in lowering the alloys" tendency to develop freckle defects over a wide range of experimental "2nd generation" single crystal alloys. Although the addition of carbon resulted in an overall reduction of grain defects, certain alloy compositions benefited more than others. Carbon additions were determined to influence the segregation behavior of the constituent alloys and affect some aspect of the mechanisms which lead to solute-induced fluid flow. DTA analyses revealed a correlation between the relative carbide dissolution temperature and the number of observed grain defects. As MC carbide formation occurred closer to the liquidus temperature, the tendency for grain defect formation decreased. Thus, alloys designed with high levels of tantalum and carbide precipitation occurring near the liquidus provide the highest degree of resistance to the breakdown of single crystal solidification.

Table II: Liquidus, Solidus and Carbide Dissolution Temperature Measurements for Experimental Single Crystal Alloys With and Without Carbon.

\begin{tabular}{c|c|c|c}
\hline Alloy & $\begin{array}{c}\text { T(solidus) } \\
{ }^{\circ} \mathbf{C}\end{array}$ & $\begin{array}{c}\text { T(carbide) } \\
{ }^{\circ} \mathbf{C}\end{array}$ & $\begin{array}{c}\text { T(liquidus) } \\
{ }^{\circ} \mathbf{C}\end{array}$ \\
\hline \hline ME1 & 1335 & - & 1397 \\
ME2 & 1333 & - & 1396 \\
ME3 & 1331 & - & 1393 \\
ME4 & 1331 & - & 1393 \\
ME5 & 1393 & - & 1426 \\
ME6 & 1396 & - & 1428 \\
ME7 & 1390 & - & 1416 \\
ME8 & 1391 & - & 1417 \\
ME9 & 1355 & 1383 & 1390 \\
ME10 & 1354 & 1378 & 1389 \\
ME11 & 1376 & 1391 & 1412 \\
ME12 & 1378 & 1391 & 1412 \\
ME13 & 1378 & 1393 & 1416 \\
ME14 & 1379 & 1393 & 1415 \\
ME15 & 1355 & 1377 & 1381 \\
ME16 & 1358 & 1378 & 1384 \\
CE1 & 1369 & - & 1402 \\
CE2 & 1370 & - & 1403 \\
CE3 & 1381 & - & 1416 \\
CE4 & 1379 & - & 1416 \\
CE5 & 1371 & 1385 & 1409 \\
CE6 & 1370 & 1385 & 1410 \\
CE7 & 1366 & 1386 & 1393 \\
CE8 & 1364 & 1385 & 1393 \\
\hline & & &
\end{tabular}

\section{Conclusions}

1) Under relatively low thermal gradients, elevated levels of Ta and intentional additions of $0.125 \mathrm{wt} \% \mathrm{C}$ improve single solidification characteristics over a wide range of compositions encompassing both " 2 nd and 3rd generation" alloys. Increasing the levels of $\mathrm{W}$ and $\mathrm{Re}$ in these alloys promotes the formation of freckle-type defects.

2) Intentional carbon additions result in the formation of Tarich $\mathrm{MC}$ carbides during solidification and alter the segregation behavior of the constituent elements.

3) Fewer freckle-type defects develop in carbon containing alloys where carbide precipitation occurs just below the liquidus temperature.

\section{References}

1. A.F. Giamei and B.H. Kear, "On the Nature of Freckles in Nickel-Base Superalloys," Metall.Trans. 1 (1970), p.2185-2192

2. T.M. Pollock, W.H. Murphy, E.H. Goldman, D.L. Uram, and J.S. Tu. "Grain Defect Formation During Directional Solidification of Nickel Base Single Crystals," Superalloys 1992. TMS. Seven Springs, PA: p.125-134

3. T.M. Pollock, "The Growth and Elevated Temperature Stability of High Refractory NickelBase Single Crystals," Mater. Sci. Eng. B32 (1995), p.255-266

4. T.M. Pollock and W.H. Murphy, "The Breakdown of Single-Crystal Solidification in High Refractory Nickel-Base Alloys," Metall. and Mat. Trans., 27A (1996), p.1081-1094

5. A.K. Sample and A. Hellawell, "The Mechanisms of Formation and Prevention of Channel Segregation During Alloy Solidification," Metall. Trans., 15A (1984), p.2163-2173

6. S.M. Copley, A.F. Giamei, S.M. Johnson, and M.F. Hornbecker, "The Origin of Freckles in Unidirectionally Solidified Castings," Metall.Trans. Vol. 1 (1970), p.2193-2204

7. P. Auburtin and A. Mitchell. "Elements of Determination of a Freckling Criterion," Proc. Symp. on Liquid Metals Processing 1996. AVS. Santa Fe, NM: p.18-34

8. S.D. Felicelli, J.C. Heinrich, and D.R. Poirier, "Simulation of Freckles During Vertical Solidification of Binary Alloys," Metall.Trans. 22B (1991), p.847-859

9. M.C. Schneider, J.P. Gu, C. Beckermann, W.J. Boettinger, and U.R. Kattner, "Modeling of Microand Macrosegregation and Freckle Formation in Single-Crystal Nickel-Base Superalloy Directional Solidification," Metall. and Mat. Trans. 28A (1997), p.1517-1531 
10. N. Streat and F. Weinberg, "Pipe Formation in PbSn Alloys," Metall. Trans. 3 (1972), p.3181-3184

11. F.L. VerSnyder and M.E. Shank, "The Development of Columnar Grain and Single Crystal High Temperature Materials Through Directional Solidification," Mater. Sci. Eng. 6 (1970), p.213247

12. S. Tin, T.M. Pollock, and W.H. Murphy. "The Role of Carbon in Directionally Solidified Superalloys," Presentation at the 1999 Fall TMS Meeting Cincinati, OH. (Submitted to Metall. and Mat. Trans.)

13. M.N. Gungor, "A Statistically Significant Experimental Technique for Investigating Microsegregation in Cast Alloys," Metall. Trans. 20A (1989), p.2529-2533

14. S.C. Huang, L. Peluso, and D. Backman. "Measurements of Solute Segregation Coefficients in Quaternary Ni-Based Superalloys, "Solidification 1999 TMS. San Diego, CA: p.163 172

15. L. Nastac, L.S. Chou, and Y. Pang. "Assessment if Solidification-Kinetics Parameters for TitaniumBase Alloys," Liquid Metals Processing Santa Fe, NM. p.207-223

16. J.R. Sarazin and A. Hellawell, "Channel Formation in $\mathrm{Pb}-\mathrm{Sn}, \mathrm{Pb}-\mathrm{Sb}$, and $\mathrm{Pb}-\mathrm{Sn}-\mathrm{Sb}$ Alloy Ingots and Comparisonn with the System $\mathrm{NH}_{4} \mathrm{Cl}-\mathrm{H}_{2} 0$," Metall. Trans. 19A (1988), p.1861-1871

17. M.C. Schneider and C. Beckermann, "A Numerical Study of the Combined Effects of Microsegregation, Mushy Zone Permeability and Flow, Caused by Volume Contraction and Thermalsolutal Convection, on Macrosegregation and Eutectic Formation in Binary Alloy Solidification," Inter. Jour. of Heat and Mass Trans. 38 (1995), p.3455-3473

18. D.R. Poirier, "Permeability for Flow of Interdendritic Liquid in Columnar-Dendritic Alloys," Metall. Trans. 18B (1987), p.245-255 